\title{
BMPR IA Downstream Genes Related to VSD
}

\author{
DEYE YANG, JIAYIN ZHANG, CHANGXI CHEN, MIN XIE, SILKE SPERLING, FEI FANG, BINXIN CHEN, XIAOWANG LI, \\ AND HUAIQIN ZHANG
}

Department of Cardiology [D.Y., J.Z., C.C., F.F., B.C., X.L., H.Z.], The First Affiliated Hospital, Institute for Cardiovascular Biology and Gene, Wenzhou Medical College, Wenzhou 325000, P.R. China; Center for Cardiovascular Development [M.X.], Baylor College of Medicine, Houston, Texas 77030; Cardiovascular Genetics [S.S.], Department Prof. H. Lehrach, Max-Planck-Institute for Molecular Genetics, 14195 Berlin, Germany

\begin{abstract}
Cardiac-specific deletion of the receptor IA of bone morphogenetic protein (BMP) (ALK3) by Cre recombinase driven under the $\alpha$-MHC promoter is lethal in mid-gestation with defects in the interventricular septum [ventricular septum defect (VSD)]. Analysis of expression of the ALK3 downstream genes is important to identify the signaling pathway for interventricular septum development. The mRNA expression level of a control group was compared with that of a test group. ALK3 downstream genes were screened using polymerase chain reaction (PCR)-select cDNA subtraction and microarray. It was found that the mice with an ALK3 knockout gene produced a VSD. The expression of some genes such as plateletactivating factor acetylhydrolase (PAF) and Pax-8 was downregulated in the test group. Pax- 8 gene expression was downregulated by 7.1 times in the test group and expressed specifically in the 11.5-d embryonic (E11.5) heart. Furthermore, the expression of the protein-tyrosine kinase of the focal adhesion kinase subfamily (PTK) and $\beta$ subtype protein 14-3-3 was up-regulated in the test group. PTK gene expression was up-regulated by 3.7 times in the test group. These data provided support that the ALK3 gene plays an important role during heart development. The PAF and Pax- 8 genes could be important ALK3 downstream genes in the BMP signaling pathway during interventricular septum development. PTK and $\beta$ subtype protein 14-3-3 might be regulatory factors in this pathway. (Pediatr Res 63: 602-606, 2008)
\end{abstract}

$\mathrm{V}$ entricular septum defect (VSD) is a common congenital heart disease. However, the underlying mechanisms and causative factors still remain unclear. Recently, certain regulatory genes for heart development, especially the genes related to VSD, have been identified. Schlange et al. and others reported that receptor IA of bone morphogenetic protein (ALK3), a member of transforming growth factor- $\beta$ (TGF $\beta$ ) superfamily, plays an important role in cardiac myocyte differentiation and heart development (1-3). Mishina et al. (4) also reported that conventional deletion of ALK3 in mice might result in early embryonic lethality. Cardiac-specific deletion of ALK3 by Cre recombinase driven under the

Received December 14, 2006; accepted May 10, 2007.

Correspondence: Deye Yang, M.D., Department of Cardiology, The First Affiliated Hospital, Institute for Cardiovascular Biology and Gene, Wenzhou Medical College, Wenzhou 325000, P.R. China; e-mail: deyeyang@hotmail.com

National Nature Science Foundation in China (30571050) and Zhejiang Province Nature Science Foundation (R303838).
$\alpha$-MHC promoter is lethal in mid-gestation with defects in the trabeculae, interventricular septum, and endocardial cushion $(5-8)$. However, ALK3 is not a cardiac-specific gene. Therefore, in this study, we sought more specific signals for ALK3 regulation of cardiac development, using the conditional knockout ALK3 mice model. We screened several ALK3 downstream genes using PCR-select cDNA subtraction and microarray and identified several candidate genes that may play a potential role in myogenesis.

\section{METHODS}

Animals. The mice $\alpha$-MHC-Cre ${ }^{+/-} \mathrm{ALK}^{\mathrm{F} /-}$ were the test group. The mice $\alpha$-MHC-Cre ${ }^{+/-} \mathrm{ALK} 3^{\mathrm{F} /+}$ were the control group. The both mice groups were generated by mating of $\alpha-\mathrm{MHC}-\mathrm{Cre}^{+/-} \mathrm{ALK} 3^{+/-} \mathrm{C} 57$ mice and ALK $3^{\mathrm{F} / \mathrm{F}} \mathrm{C} 57$ mice. The animal study was approved by the Animal Welfare Committee of Wenzhou Medical College following state and institutional regulations.

RNA extraction and analysis by PCR-select cDNA subtraction. Total RNA and mRNA were extracted from the E11.5 hearts in the test group and control group ( $n=8$, each group) using an RNA extraction kit (QIAGEN, Valencio, CA) according to the manufacturer's instructions. Two populations of mRNA, one derived from the E11.5 hearts of $\alpha-\mathrm{MHC}-\mathrm{Cre}^{+/-} \mathrm{ALK} 3^{\mathrm{F} /-}$ mice and the other derived from the hearts of $\alpha$-MHC $\mathrm{Cre}^{+/-} \mathrm{ALK}^{\mathrm{F} /+}$ mice at the same ages, were analyzed using PCR-select cDNA subtraction kit (Clontech, Palo Alto, CA) (9). The quantity of mRNA used for analysis was $0.8 \mu \mathrm{g}$ per experiment. The RNA integrity was determined by $1 \%$ agarose electrophoresis with ethidium bromide or measured spectrometrically at A260/A280 nm.

Microarray gene screening. The mRNA expression profile was analyzed and compared in both animal groups using the microarray technique described previously (10). In brief, ALK3 downstream genes were screened using microarray that includes 25,000 genes made in Max-Planck-Institute for Molecular Genetics, Berlin, Germany. The cDNA arrays represented by 3 Hybond $\mathrm{N}^{+}$membranes containing PCR products of 25,000 different IMAGE clones spotted in duplicate. Labeling was performed by reverse transcription (RT) of $1 \mu \mathrm{g}$ mRNA with avian myoblastosis virus reverse transcriptase (AMV-RT; Promega) in the presence of $\operatorname{pd}(\mathrm{T})_{12-18}$ (Amersham Pharmacia Biotech) and $\alpha^{33} \mathrm{P}$-dCTP (Amersham Pharmacia Biotech). Unincorporated nucleotides were removed using ProbeQuant G-50 microcolumns (Amersham Pharmacia Biotech), and cDNA was added to the hybridization solution together with salmon sperm DNA (GIBCO BRL), placenta DNA, and pd(A) $)_{40}$ (MWG Biotech). Hybridizations were performed at $65^{\circ} \mathrm{C}$ for $16 \mathrm{~h}$. After

\footnotetext{
Abbreviations: ALK3, receptor IA of bone morphogenetic protein; BMP, bone morphogenetic protein; PAF, platelet-activating factor acetylhydrolase; Pax-8, paired box gene 8; PTK, protein-tyrosine kinase of the focal adhesion kinase subfamily; TGF $\boldsymbol{\beta}$, transforming growth factor $\beta$; VSD, ventricular septum defect
} 
washing, arrays were exposed for $24 \mathrm{~h}$ and scanned using a Fuji Film Bas-1800 reader (Fuji photo film). Image analysis was carried out using the $\mathrm{X}$-Digitize image processing software. Data normalization was principally performed as described previously. After local background subtraction, all intensity values below 200 were reset to this level and the intensities of each hybridization were scaled to a constant sum. Visual inspection showed that the variance of the resulting log-transformed intensities was approximately constant across the intensity range. Because the hybridizations were performed on arrays from two different production batches, which significantly affected the measurements, we corrected the influence of the production batch as follows. We considered two virtual reference hybridizations, defined by the spotwise medians of 10 hybridizations from the respective array batch. The logarithms of ratios between the intensities of each hybridization of interest and those of the respective batch-specific virtual reference hybridization were shifted such that the median over the $40 \%$ of spots with highest average $\log$-intensity became 0 . Finally, the obtained log-ratio (base 10) values were averaged over duplicate spots per clone, resulting in values that are referred to as normalized expression levels in the text. The $1 \mu \mathrm{g}$ mRNA of the control group was extracted from $10 \mathrm{E} 11.5$ hearts with $\alpha$-MHC-Cre ${ }^{+/-} \mathrm{ALK}_{3}^{\mathrm{F} /+}$ genotype, and $1 \mu \mathrm{g}$ mRNA from $10 \mathrm{E} 11.5$ hearts with $\alpha$-MHC-Cre ${ }^{+/-}$ $\mathrm{ALK}^{\mathrm{F} /-}$ genotype in the test group.

Real-time quantitative RT-PCR. Quantitative RT-PCR was performed with a TaqMan One step PCR core kit (Perkin-Elmer, Wellesley, MA) (11). The cDNA was synthesized from 100 ng of total RNA by RT at $48^{\circ} \mathrm{C}$ for 30 min by random hexamer. Three reactions were performed for one RNA sample. The cDNA products were amplified for a total of 40 cycles of PCR, the first denaturation for $10 \mathrm{~min}$ at $95^{\circ} \mathrm{C}$, with each cycle consisting of denaturation for $15 \mathrm{~s}$ at $95^{\circ} \mathrm{C}$, annealing, and extension for $1 \mathrm{~min}$ at $60^{\circ} \mathrm{C}$, respectively. A novel quantitative PCR method was developed by the use of real-time detection and 5' nuclease assay by an ABI PRISM 7700 sequence detector (Perkin-Elmer). The following primers and probes were used for quantification of targeted gene expression: for Pax-8: probe 5' 6FAM TGT CCC CAG TGT CAG CTC CAT CAA CA TAMRA 3', forward primer 5' CAG AAG GCG TTT GTG ACA ATG A 3', and reverse primer 5' GCA CTT TGG TCC GGA TGA TT $3^{\prime}$; for the protein tyrosine kinase of focal adhesion kinase subfamily (PTK): probe 6 FAM-TGC CTT GCC TTT GGT TAT TGG TCT TCC -TAMRA, forward primer $5^{\prime}$ CCA CCT GTC TTG GCA TAC CTT T $3^{\prime}$, and reverse primer $5^{\prime}$ GGA TGG ACT CTT CTC AGC TTT CC $3^{\prime}$; for 36B4 probe 6FAM-CCA GGC TTT GGG CAT CAC CAC G-TAMRA, forward primer 5' GGA CCC GAG AAG ACC TCC TT 3', and reverse primer 5' TCA ATG GTG CCT CTG GAG ATT 3'.

In situ hybridization. The E11.5 mouse embryos derived from the test and control group mice were used to make whole mount and section in situ hybridization (12). The embryos used for section in situ hybridization were fixed in $4 \%$ paraformaldehyde for $20 \mathrm{~h}$. The embryos used for whole mount in situ hybridization were fixed in MEMFA (including 3.7\% formaldehyde) for $90 \mathrm{~min}$ at room temperature. The mouse antisense paired box gene 8 (Pax-8) RNA was derived from plasmid (PBluescript II KS-Pax-8/E.CORV that was cut by E.CORV and transcripted by T7 polymerase). The r-UTP labeling digoxin (Roche, Mannheim, Germany) was used in RNA synthesis. The mouse sense Pax-8 RNA was derived from plasmid (PBluescript 11 KS-pax-8/BamH I that was cut by BamHI and transcripted by T3 polymerase). The length of Pax-8 probe was 449 bp (2039 - 1590 bp). Hybridization was carried out at $42^{\circ} \mathrm{C}$ overnight. The hybrids were visualized by incubating with an immunostaining system containing Dig-Fab antibody and NBT/BCIP (Roche).

\section{RESULTS}

Embryogenesis of cardiac-specific ALK3 knockout mice. Because homozygous ALK3-null mice died during embryonic development, we obtained the embryos of the $\alpha$-MHC- $-\mathrm{Cre}^{+/-}$ $\mathrm{ALK}^{\mathrm{F} /-}$ and $\alpha$-MHC-Cre ${ }^{+/-} \mathrm{ALK}^{\mathrm{F} /+}$ mice embryos by crossing female $\alpha$-MHC-Cre ${ }^{+/-} \mathrm{ALK}^{+/-}$mice and male $\mathrm{ALK}^{\mathrm{F} / \mathrm{F}}$ mice mating (Fig. 1). Cardiac-specific deletion of ALK3 by Cre recombinase driven under the $\alpha$-MHC promoter is lethal in mid-gestation with defects in the interventricular septum (Fig. 2).

Identification of ALK3 downstream genes by PCR-select cDNA subtraction. Using PCR-select cDNA subtraction, we screened several genes downstream of ALK3 as listed in Table 1. We observed that expression of the PAF mRNA was

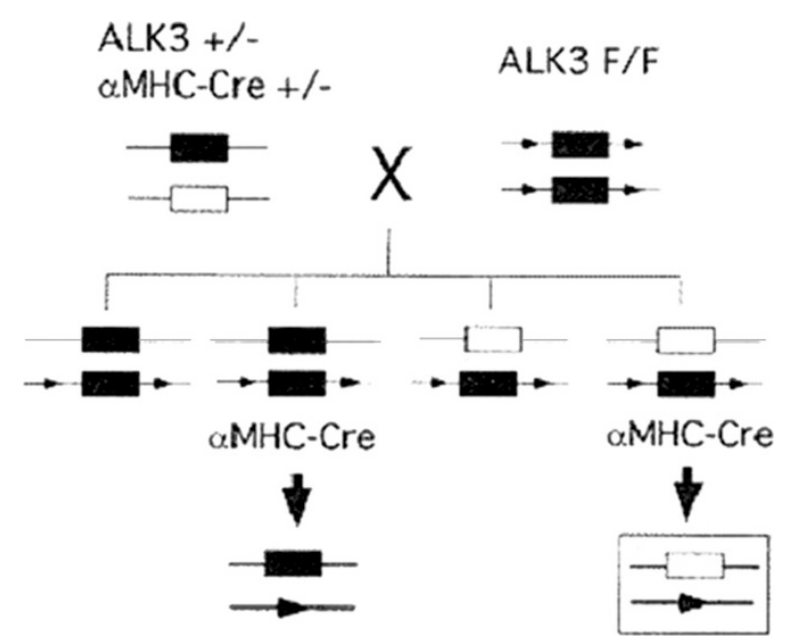

Figure 1. Sketch map of cardiac-specific deletion of ALK3 gene. ALK3 gene

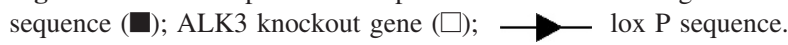
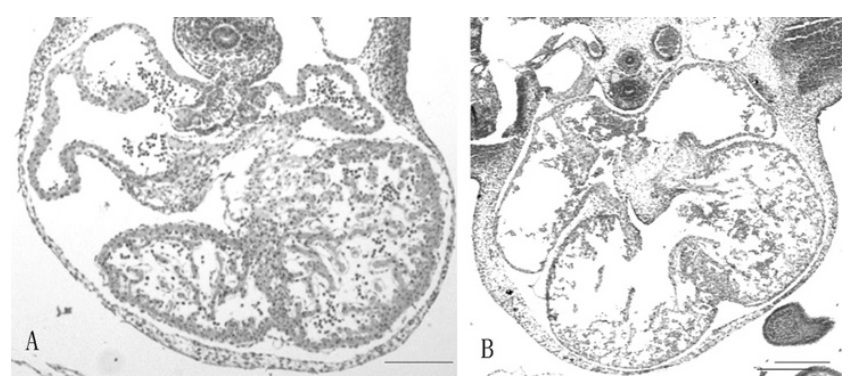

Figure 2. The phenotype of cardiac-specific deletion of ALK3 gene. (A) $\alpha-\mathrm{MHC}-\mathrm{Cre}^{+/-} \mathrm{ALK} 3^{\mathrm{F} /+} \mathrm{E} 11.5$ mice embryonic heart section is normal. $(B)$ $\alpha-\mathrm{MHC}-\mathrm{Cre}^{+/-} \mathrm{ALK}^{\mathrm{F} /-}$ E11.5 mice embryonic heart section with VSD. Scale bars $=0.5 \mathrm{~mm}(A, B)$.

Table 1. The downstream genes of $A L K 3$ down-regulated in the test group mice by PCR-select cDNA subtraction

\begin{tabular}{ll}
\hline \multicolumn{1}{c}{ Gene } & Clone \\
\hline PAF & R-D12 \\
Rat testis-specific farnesyl pyrophosphate synthetase & R-B4 \\
MCM protein & R-D1 \\
EST & R-A8 \\
EST & R-B2 \\
\hline
\end{tabular}

Table 2. The downstream genes of ALK3 up-regulated in the test group mice by PCR-select cDNA subtraction

\begin{tabular}{ll}
\hline \multicolumn{1}{c}{ Gene } & Clone \\
\hline 14-3-3 protein $\beta$ subtype & F-A8 \\
Serine/threonine protein phosphatase type $1 \alpha$ & F-A1 \\
Phospholipase C- $\alpha$ & F-G4 \\
Retinoblastoma-binding protein & F-H2 \\
Ruv B-like protein 2 & F-A2 \\
EST & F-H5 \\
\hline
\end{tabular}

significantly reduced in the E11.5 $\alpha$-MHC-Cre ${ }^{+/-} \mathrm{ALK} 3^{\mathrm{F} /-}$ embryonic heart compared with the wild-type control (Table 1). On contrary, the $\beta$ subtype protein 14-3-3 mRNA was up-regulated in the E11.5 $\alpha$-MHC $\mathrm{Cre}^{+/-} \mathrm{ALK}^{\mathrm{F} /-}$ embryonic heart (Table 2).

Identification of ALK3 downstream genes by microarray. We further studied expression of 25,000 genes in $\alpha$-MHC- 
Table 3. The downstream genes of ALK3 down-regulated in the test group mice by microarray

\begin{tabular}{lc}
\hline \multicolumn{1}{c}{ Gene } & $\begin{array}{c}\text { Fold } \\
\text { down-regulated }\end{array}$ \\
\hline Myoglobin & 46.2 \\
Pax-8 & 5.7 \\
Phospholamban & 10.1 \\
Ubiquitin-conjugating enzyme E2 & 4.4 \\
Ring zinc finger protein & 4.7 \\
G protein-coupled receptor & 5.5 \\
Deoxycytidine kinase & 4.0 \\
Plasminogen activator inhibitor & 4.1 \\
Rab11b & 2.7 \\
Hox-3.5 & 4.0 \\
Transcription factor IIF $\beta$ subunit & 2.7 \\
Musculus growth/differentiation factor 1 & 2.7 \\
\hline
\end{tabular}

Table 4. The downstream genes of ALK3 up-regulated in the test group mice by microarray

\begin{tabular}{lc}
\multicolumn{1}{c}{ Gene } & $\begin{array}{c}\text { Fold } \\
\text { up-regulated }\end{array}$ \\
\hline Ras-related protein Rab-5b & 7.0 \\
EPS 8 protein & 2.4 \\
A protein tyrosine kinase of the focal adhesion & 5.4 \\
$\quad$ kinase subfamily & \\
Galectin-9 & 4.9 \\
K-glypican & 4.7 \\
WNT-2 protein precursor & 4.5 \\
Plakoglobin & 4.2 \\
Epidermal growth factor receptor kinase substrate & 4.0 \\
Interferon regulatory factor 1 & 5.7 \\
Mdm2 protein & 2.5 \\
Ras-related protein RAC1 & 2.0 \\
Ras-related protein (Krev-1) & 2.3 \\
Transcriptional activator FE65 & 2.5 \\
Suppressor of MIF2 mutations & 2.5 \\
Elongation factor 1 $\gamma$ & 4.0 \\
Regulator of G-protein signaling 16 & 13.2 \\
\hline
\end{tabular}

$\mathrm{Cre}^{+/-} \mathrm{ALK}^{\mathrm{F} /-}$ (test group) and $\alpha-\mathrm{MHC}-\mathrm{Cre}^{+/-} \mathrm{ALK}^{\mathrm{F} /+}$ (control group) using the microarray technology. The change in the level of gene expression over twofold was considered positive. We found that there were significant reductions in expression of 12 genes (Table 3), whereas there were 16 genes up-regulated in test group (Table 4).

RT-PCR verification of ALK3 downstream genes. To confirm the changes in those selected genes, we performed RTPCR with the same amounts of RNA derived from the test group and the control group. The PCR was performed using gene-specific primers for each gene. The quantity of PCR product was compared with respect to glyceraldehyde-3phosphate dehydrogenase (GAPDH), which served as a control gene. The results showed that the quantities of PCR product of PAF at the 21th PCR cycle and Pax-8 at the 27th PCR cycle in the test group were lower than those in the control group. The expression of two genes was downregulated in the test group (Fig. 3). The quantity of PCR product of 14-3-3 protein $\beta$ subtype at the 23rd cycle and PTK at the 21st PCR cycle in the test group was much more than that in the control group. Therefore, 14-3-3 protein $\beta$ subtype and PTK gene expression in the test group was up-regulated (Fig. 4).

\section{Cre $+/-$, ALK3 F $/-\quad$ Cre $+/-$, ALK3 F $/+$}

$\begin{array}{llllllllll}19 & 21 & 23 & 25 & 27 & 19 & 21 & 23 & 25 & 27 \text { (PCR cycle) }\end{array}$

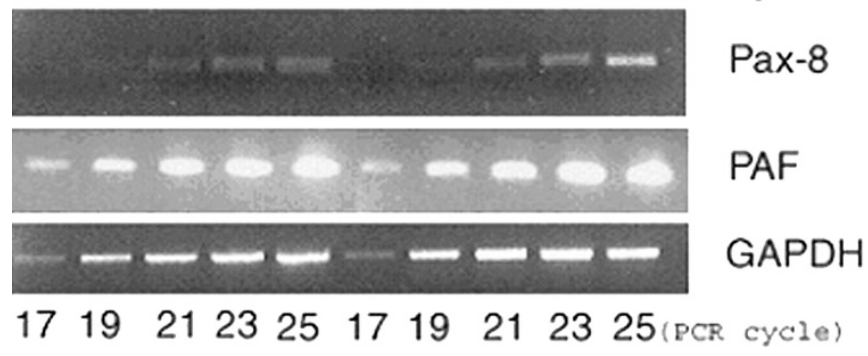

Figure 3. The gene expression level of Pax- $8, \mathrm{PAF}$, and GAPDH in the test and control groups. $\mathrm{Cre}^{+/-} \mathrm{ALK} 3^{\mathrm{F} /-}$ is the test group; $\mathrm{Cre}^{+/-}, \mathrm{ALK}^{\mathrm{F} /+}$ is the control group.

Cre+/-, ALK3 F/- Cre+/-, ALK3 F/+

19212325271921232527 (PCR cycle)

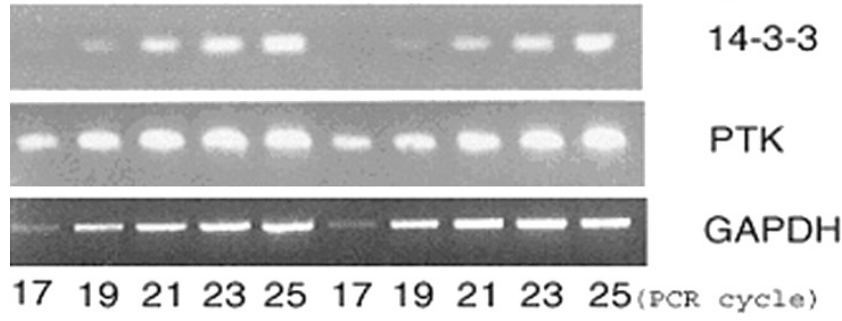

Figure 4. The gene expression level of the 14-3-3 PTK and GAPDH in test and control groups. $\mathrm{Cre}^{+/-} \mathrm{ALK} 3^{\mathrm{F} /-}$ is the test group; $\mathrm{Cre}^{+/-} \mathrm{ALK} 3^{\mathrm{F} /+}$ is the control group.

Real-time quantitative RT-PCR. Real-time quantitative RT-PCR further confirmed that Pax- 8 gene expression in the test mice was lower than in the control mice by 7.1 times as detected by real-time quantitative RT-PCR $(p<0.001)$. There was no difference in the expression of the 36B4 gene, the internal control, between the test group and the control group (Fig. 5). PTK gene expression in the test group mice was higher than that in the control group mice by 3.7 times as detected by real-time quantitative RT-PCR $(p<0.01)$ (Fig. 6). Expression of the PAF and 14-3-3 genes was not significantly different between the test group and the control group mice (data not shown).

Localization of ALK3 downstream genes in embryos by in situ hybridization. In the E11.5 embryo whole mount in situ hybridization, we found that Pax-8 was expressed in the $\alpha-\mathrm{MHC}-\mathrm{Cre}^{+/-} \mathrm{ALK}^{\mathrm{F} /+}$ E11.5 heart, but not in the $\alpha$-MHC$\mathrm{Cre}^{+/-} \mathrm{ALK}^{\mathrm{F} /-}$ E11.5 heart (Fig. 7). In E11.5 embryonic heart, the four-chamber in section in situ hybridization showed that Pax- 8 was present in the $\alpha-\mathrm{MHC}-\mathrm{Cre}^{+/-} \mathrm{ALK}^{\mathrm{F} /+} \mathrm{E} 11.5$ mice whole heart, including the right and left atrium and ventricles. However, this gene was almost undetectable in the $\alpha-\mathrm{MHC}-\mathrm{Cre}^{+/-} \mathrm{ALK}^{\mathrm{F} /-}$ E11.5 mice heart (Fig. 8).

\section{DISCUSSION}

BMP is a secreted signaling molecule belonging to the TGF $\beta$ superfamily of growth factors. Its multiple physiologic functions include the regulation of cell proliferation and differentiation, apoptosis, morphogenesis, patterning of various organs including the skeleton, and organogenesis. Once se- 

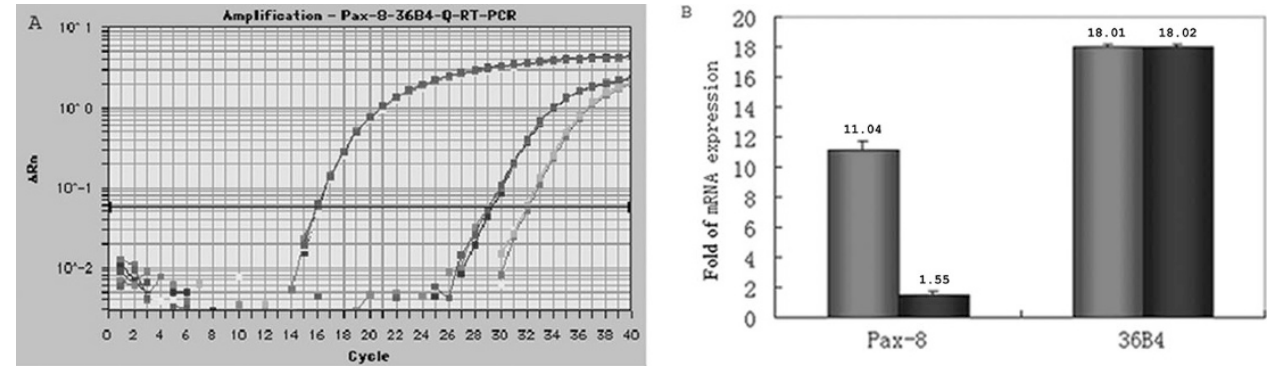

Figure 5. Comparison of Pax-8 gene expression level using quantitative RT-PCR. (A) The data show the real time curve of quantitative RT-PCR. (B) Columns to the left of each pair show the data from $\alpha-\mathrm{MHC}-\mathrm{Cre}^{+/-} \mathrm{ALK}^{\mathrm{F} /+}$ mice. Columns to the right of each pair show the data from $\alpha$-MHC-Cre ${ }^{+/-} \mathrm{ALK}^{\mathrm{F} /-}$ mice. $36 \mathrm{~B} 4$ is a quantitative RT-PCR internal control gene.

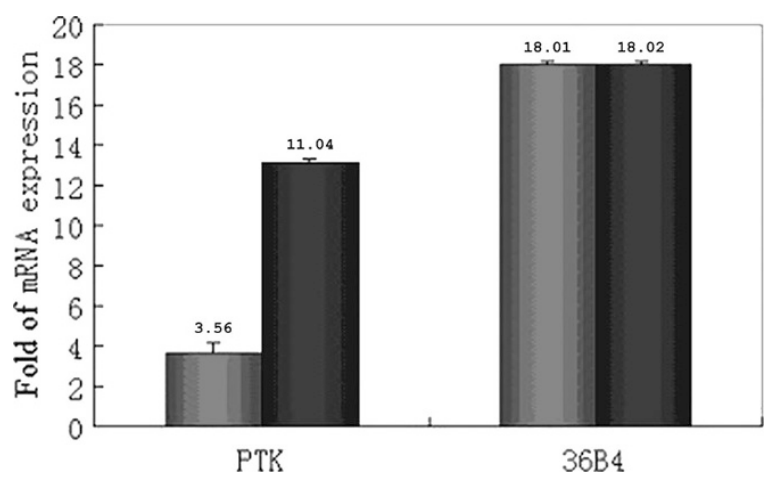

Figure 6. Comparison of the PTK gene expression level using quantitative RT-PCR. Columns to the left of each pair show the data from $\alpha$-MHC-Cre ${ }^{+/}$ $-\mathrm{ALK}_{3}{ }^{\mathrm{F} /+}$ mice. Columns to the right of each pair show the data from $\alpha$-MHC-Cre ${ }^{+/-} \mathrm{ALK}^{\mathrm{F} /-}$ mice. 36B4 is a quantitative RT-PCR internal control gene.

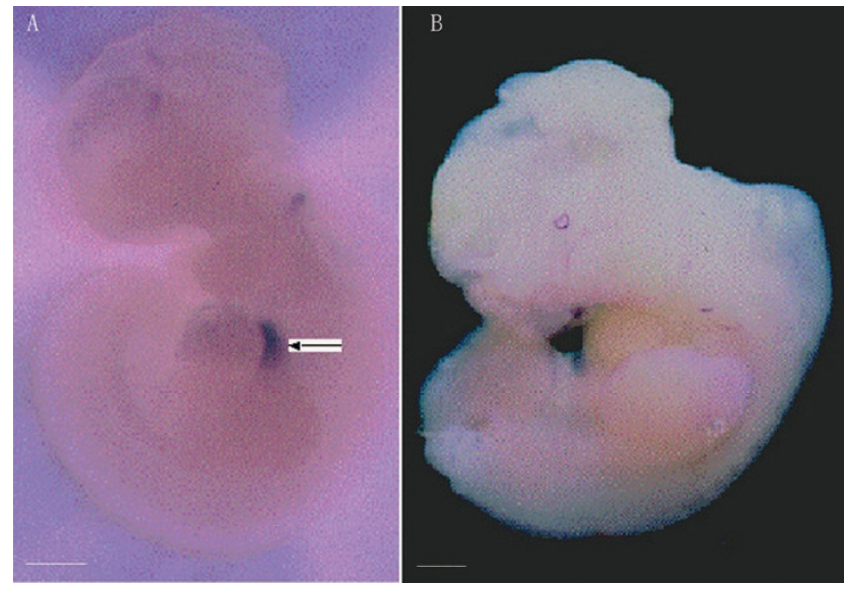

Figure 7. The Pax-8 gene expression in the E11.5 mice embryo as detected using in situ hybridization. (A) $\alpha$-MHC-Cre ${ }^{+/-} \mathrm{ALK}^{\mathrm{F} /+} \mathrm{E} 11.5$ mice heart is dyed to deep blue. $(B) \alpha$-MHC-Cre ${ }^{+/-} \mathrm{ALK}^{\mathrm{F} /-}$ E11.5 mice. Scale bars $=1$ $\mathrm{mm}(A, B)$.

creted, the BMPs fulfill their signaling function by binding to a heterodimeric complex of two transmembrane receptors, termed type I and type II, with serine-threonine kinase activity. ALK3 acts as the type IA receptor of BMP and thus plays a role in the regulation of heart development. Cardiac-specific deletion of ALK3 can be achieved using the $\alpha$-MHC-Cre/lox $\mathrm{P}$ system (cardiac-specific $\alpha$-MHC is a Cre recombinase promoter). Primary study shows that ALK3 is an important related gene during interventricular septum development. As an upstream signaling molecule, ALK3 has an impact on expression of many other genes downstream of the BMP pathway. In this study, we have shown that the 17 genes were down-regulated and the 22 genes were up-regulated in
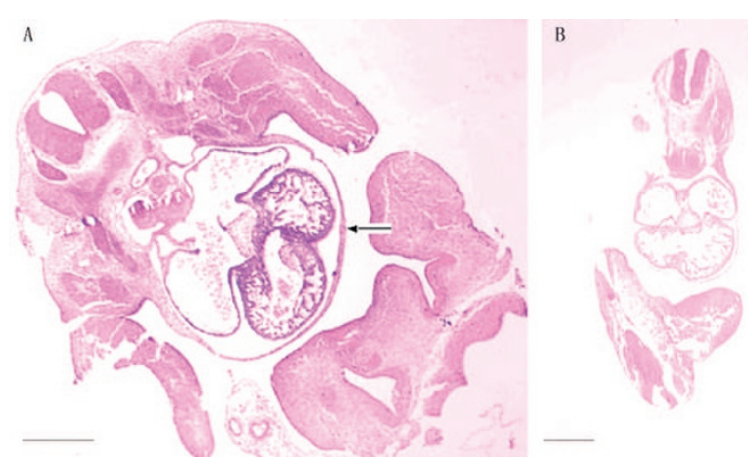

Figure 8. The Pax-8 gene expression in E11.5 mice heart as detected using in situ hybridization. (A) $\alpha$-MHC-Cre ${ }^{+/-} \mathrm{ALK}^{\mathrm{F} /+} \mathrm{E} 11.5$ mouse section. The arrow shows the position of heart. (B) $\alpha$-MHC-Cre ${ }^{+/-} \mathrm{ALK}^{\mathrm{F} /-} \mathrm{E} 11.5$ mice section. Scale bars $=1 \mathrm{~mm}(A, B)$.

the test group in E11.5 hearts identified by PCR-select cDNA subtraction and microarray. The RT-PCR reaction was performed using gene-specific primers for the 36 genes, except three EST genes. We found that only the expression of PAF and Pax- 8 genes was down-regulated and the expression of 14-3-3 protein $\beta$ subtype and PTK genes was up-regulated in the test group. These four genes confirmed by RT-PCR were further examined by real-time quantitative RT-PCR. It has been reported that the Pax- 8 gene is reduced by 7.1 times using real-time quantitative RT-PCR and expressed specifically in the embryonic heart (11.5 d). Conversely, PTK was up-regulated by 3.7 times in the E11.5 heart with cardiac-specific deletion by real-time quantitative RT-PCR. However, we found that there was no significant change in the PAF and 14-3-3 protein $\beta$ subtype genes (data not shown).

Both PCR-select cDNA subtraction and microarray assays are frequently used for high-throughput screening of genes involved in embryonic development. Our study clearly indicates that as the most advanced and quickest gene-profiling methods, they provide us a strong tool to analyze gene expression potentially regulated by ALK3. However, there are certain limitations to the application of the gene-profiling methods, as they are relatively less sensitive for detection of genes at lower abundance and should be cleared of potentially false-positive or -negative results. To overcome these pitfalls, we used other methods to confirm the results, such as RT-PCR and real-time quantitative RT-PCR. The results from both methods appear to be consistent and reproducible. Further studies on the functional alterations in gene expression are under way in our group. 
Acknowledgment. We thank Dr. Michael D. Schneider for technical advice and for providing animals.

\section{REFERENCES}

1. Schlange T, Andree B, Arnold HH, Brand T 2000 BMP2 is required for early heart development during a distinct time period. Mech Dev 91:259-270

2. Monzen K, Shiojima I, Hiroi Y, Kudoh S, Oka T, Takimoto E, Hayashi D, Hosoda T, Habara-Ohkubo A, Nakaoka T, Fujita T, Yazaki Y, Komuro I 1999 Bone morphogenetic proteins induce cardiomyocyte differentiation through the mitogenactivate protein kinase kinase kinase TAK1 and cardiac transcription factors Csx/ NKx-2.5 and GATA-4. Mol Cell Biol 19:7096-7105

3. Beppu H, Kawabata M, Hamamoto T, Chytil A, Minowa O, Noda T, Miyazono K 2000 BMP type ii receptor is required for gastrulation and early development of mouse embryos. Dev Biol 221:249-258

4. Mishina Y, Suzuki A, Ueno N, Behringer RR 1995 BMPR encodes a type I bone morphogenetic protein receptor that is essential for gastrulation during mouse embryogenesis. Genes Dev 9:3027-3037

5. Fukushipe S, Ikoda JE 1996 Trapping of mammalian promoters by Cre-lox sitespecific recombination. DNA Res 3:73-80

6. Gaussin V, Van de Putte T, Mishina Y, Hanks MC, Zwijsen A, Huylebroeck D, Behringer RR, Schneider MD 2002 Endocardial cushion and myocardial defects after cardiac myocyte-specific conditional deletion of the bone morphogenetic protein receptor ALK3. Proc Natl Acad Sci U S A 99:2878-2883

7. Schneider MD, Gaussin V, Lyons KM 2003 Tempting fate: BMP signals for cardiac morphogenesis. Cytokine Growth Factor Rev 14:1-4

8. Gaussin V, Morley GE, Cox L, Zwijsen A, Vance KM, Emile L, Tian Y, Liu J, Hong C, Myers D, Conway SJ, Depre C, Mishina Y, Behringer RR, Hanks MC, Schneider MD, Huylebroeck D, Fishman GI, Burch JB, Vatner SF 2005 Alk3/Bmpr 1a receptor is required for development of the atrioventricular canal into valves and annulus fibrosus. Circ Res 97:219-226

9. Diatchenko L, Lau YF, Campbell AP, Chenchik A, Moqadam F, Huang B, Lukyanov S, Lukyanov K, Gurskaya N, Sverdlov ED, Siebert PD 1996 Suppression subtractive hybridization: a method for generating differentially regulated or tissue-specific cDNA probes and libraries. Proc Natl Acad Sci U S A 93:60256030

10. Pollak ES, Feng L, Ahadian H, Fortina P 2001 Microarray-based genetic analyses for studying susceptibility to arterial and venous thrombotic disorders. Ital Heart J 2:568-572

11. Gibson UE, Heid CA, Williams PM 1996 A novel method for real time quantitative RT-PCR. Genome Res 6:995-1001

12. Sato TN, Tozawa Y, Deutsch U, Wolburg-Buchholz K, Fujiwara Y, Gendron Maguire M, Gridley T, Wolburg H, Risau W, Qin Y 1995 Distinct roles of the receptor tyrosine kinases Tie-1 and Tie-2 in blood vessel formation. Nature 376:70-74 